УДК 636.4

06.00.00 Сельскохозяйственные науки

ВОСПРОИЗВОДИТЕЛЬНЫЕ, ОТКОРМОЧНЫЕ И МЯСНЫЕ КАЧЕСТВА МОЛОДНЯКА СВИНЕЙ ПРИ

ИСПОЛЬЗОВАНИИ ХРЯКОВ

СПЕЦИАЛИЗИРОВАННЫХ ПОРОД И ТИПОВ

Леонидов Иван Николаевич аспирант

Козликин Алексей Викторович

к.с.-Х.Н., доцент

РИНЦ SPIN-код: 8272-4655

Лодянов Вячеслав Викторович

к.с.-Х.Н., доцент

РИНЦ SPIN-код: 9058-3850

Донской государственный аграрный университет, n. Персиановский, Россия

Приведена оценка воспроизводительных, откормочных и мясных качеств чистопородных свиней крупной белой породы (КБ), двухпородных помесных маток, полученных от скрещивания свиноматок КБ с хряками степного типа (СТ) СМ-1 и трёхпородных животных, полученных скрещиванием помесных маток КБ х СТ с хряками специализированных импортных мясных пород ландрас (Л), дюрок (Д) и пьетрен (П). Изучены такие качества, как многоплодие, молочность, живая масса гнезда, средняя масса одного поросенка, сохранность приплода к отъему, скороспелость, которая тесно связана со среднесуточным приростом живой массы, мясность туш, их линейные размеры, мясная продуктивность, количество почечного жира, масса туш у животных подопытных групп, убойный выход

Ключевые слова: СВИНЬИ, МЯСО, МНОГОПЛОДИЕ, МОЛОЧНОСТЬ, ЖИВАЯ МАССА ГИБРИДИЗАЦИЯ, ПОРОДЫ И ТИПЫ СВИНЕЙ

Doi: 10.21515/1990-4665-122-008
UDC 636.4

Agricultural science

\section{REPRODUCTIVE, FATTENING AND MEAT \\ QUALITIES OF YOUNG PIGS AT USING BOARS OF SPECIALIZED BREEDS AND TYPES}

Leonidov Ivan Nikolaevich
postgraduate student

Kozlikin Alexey Viktorovich

Cand.Agr.Sci., associate professor SPIN-code: $8272-4655$

Lodianov Viacheslav Viktorovich Cand.Agr.Sci., associate Professor SPIN-code: $9058-3850$

Don state agrarian University, p. Persianovka, Russia

The article describes the evaluation of reproductive, fattening and meat qualities of pigs of purebred large white breed (KB), crossbred ewes, derived from crosses KB sows with boars of steppe type (ST) CM-1 and three-pedigree animals, obtained by crossing crossbred ewes KB x ST with imported boars of specialized meat breeds, such as Landrace (L) Duroc (D) and pietrain (P). We have studied qualities such as prolificacy, milk yield, live weight of the nest, the average weight of one Piglet, the safety of the offspring to weaning, maturity, which is closely associated with average daily gain in live weight, meat content of carcasses, their linear dimensions, meat productivity, the amount of kidney fat, weight of carcasses of animals of the experimental groups, carcass yield

Keywords: PIG, MEAT, PROLIFICACY, MILK YIELD, LIVE WEIGHT HYBRIDIZATION, BREED AND TYPES OF PIGS

Общемировыми тенденциями в мировом свиноводстве на ближайшую перспективу будут являться следующие процессы: интенсивные наукоемкие технологии с минимальными издержками производства; генная инженерия; интеграция производителей свинины; 
гибридизация свиней; укрупнение хозяйств, уменьшение персонала при обслуживании животных и увеличение объемов производства [4].

Исследование отечественных и зарубежных исследователей свидетельствуют о целесообразности производства мясной свинины и повышении мясных качеств помесного молодняка с использованием крупной белой породы и о высоких откормочных качеств трехпородных помесей, полученных при использовании хряков пород дюрок, ландрас и пьетрен $[1,3,7]$.

Одним из путей увеличения производства свинины и снижения ее себестоимости является применение межпородного скрещивания. При оптимальных условиях кормления и содержания мясность свиней на $67 \%$ определяется их генотипическими особенностями и только на $33 \%$ - всем остальным $[2,5,6,8,9]$.

Изучались показатели воспроизводительных качеств с использованием маток крупной белой породы и помесных маток (КБ хСТ) при скрещивании с хряками П, Л и Д. Результаты исследований свидетельствуют об определенных различиях между группами по показателям, характеризующим репродуктивные качества свиноматок.

Экспериментальная часть исследований выполнена в период 20132016 гг. В опытах использовались чистопородные свиноматки крупной белой породы (КБ) и помесные свинки КБ х степной тип (СТ), помесные подсвинки, полученные при использовании хряков дюрок (Д), ландрас (Л), пьетрен (П) и скороспелой мясной пород (CM-1). Исследования проводились по следующей схеме (табл. 1): 
Таблица 1 - Схема опыта

\begin{tabular}{|l|l|c|c|c|c|}
\hline \multirow{2}{*}{ № } & \multirow{2}{*}{ Группа } & \multicolumn{2}{|c|}{ Вариант подбора } & \multicolumn{2}{c|}{ Количество голов } \\
\cline { 3 - 6 } & & матки & хряки & маток & хряков \\
\hline 1 & контрольная & КБ & КБ & 12 & 3 \\
\hline 2 & опытная & КБ & СТ & 12 & 3 \\
\hline 3 & опытная & КБ х СТ & П & 12 & 3 \\
\hline 4 & опытная & КБ х СТ & Л & 12 & 3 \\
\hline 5 & опытная & КБ х СТ & Д & 12 & 3 \\
\hline
\end{tabular}

Согласно схемы опыта было сформировано 5 групп свиноматок:

1гр. - чистопородные свиноматки КБ; 2 гр. - помесные матки КБ х СТ; 3 , 4, 5 группы помесные свиноматки КБ х СТ с закреплением за ними хряков соответствующих пород: пьетрен (П), дюрок (Д), ландрас (Л).

Формирование контрольной и опытных групп проводили по принципу аналогов, с учетом возраста и развития животных (использовались свиноматки первоопороски).

Свиноматки покрывались дважды в одну охоту одним и тем же хряком - сразу после выявления охоты и повторно через 24 часа. Первые три дня после покрытия свиноматки содержались в индивидуальных станках, а затем в групповых клетках.

Воспроизводительные качества характеризуются комплексом признаков: многоплодием, молочностью, живой массой гнезда, средней массой одного поросенка, сохранностью приплода к отъему.

Многоплодие является одним из важных селекционных признаков, которое определяется количеством живых поросят при рождении.

По этому показателю свиноматки 4 и 5 групп превосходили сверстников КБ на 0,7 и 0,6 гол. (P<0,95), а свиноматок 2 группы соответственно на 0,6-0,5 гол. (P<0,95). Сравнение многоплодия помесных маток КБ х СТ при скрещивании с хряками П, Л и Д показало, что животные 4 и 5 группы по этому показателю имели преимущество над 3 группой на 0,5-0,4 (P<0,95) поросенка. 
Молочность свиноматок определяется массой гнезда поросят в возрасте 21 день. В это период рост и развитие поросят во многом зависит от молочности свиноматок. Поэтому в этом возрасте (21 день) необходимо избегать физических, технологических и кормовых факторов, которые неблагоприятно влияют на молочную продуктивность маток и сохранность поросят.

Наиболее высокой молочной продуктивностью обладали помесные матки КБ х СТ в сочетании с хряками пьетрен, ландрас, дюрок, которые имели достоверное преимущество в сравнение с контрольной группой на 5,9; 6,8 и 6,6 кг (Р>0,999). При этом необходимо отметить, что среди вариантов 3-породного скрещивания лучшие результаты по молочности были у помесных маток КБ х СТ при спаривании с хряками ландрас - 56,3 кг, затем следуют свиноматки 5 и 3 группы - 56,1 и 55,4 кг. Свиноматки КБ при скрещивании с хряками СТ, по молочности имели показатели ниже, чем помесные свиноматки 3, 4 и 5 групп соответственно на 9,6; 11,1 и $10,7 \%$.

Лучшая сохранность к 2-х месячному возрасту оказалась у помесных поросят 5 группы, которая составила 88,5 против 86,8\% в контроле. Высокая сохранность приплода также отмечена в 3 и 4 группах $88,0-87,6 \%$ или на 1,3 и 0,9\% выше, чем у сверстников чистопородного разведения.

Наибольшая живая масса гнезда при рождении была у помесных поросят от трехпородного скрещивания 12,0; 12,6 (Р>0,99) и 13,5 кг (Р>0,999) или на 0,3; 0,9 и 1,8 кг выше сверстников чистопородного разведения.

Одним из основных критериев репродуктивных качеств свиноматок является живая масса гнезда в 2-месячном возрасте, которая составила при двухпородном скрещивании - 153,9 кг, а в разных вариантах 
трехпородного скрещивания 160,2; 170,2; 171,1 кг (Р>0,95 - 0,999), что на 7,1 - 14,4\% выше, чем при чистопородном разведении.

По средней массе одного поросенка к отъему подопытный молодняк имел следующие показатели: более крупными были поросята 3 , 4 и 5 группы - 18,2; 18,5; 18,6 кг, что достоверно выше, чем у животных 1 группы на 3,4\% (P>0,95); 5,1\% (P>0,99) и 5,7\% (P>0,999).

Самый большой абсолютный и среднесуточный приросты за 2 месяца подсосного периода были у поросят 3, 4, 5 групп, что на 3,7 - 6,2\% выше, чем у животных контрольной группы.

Наибольшая интенсивность роста и относительный прирост был у подсвинков 2, 3 и 5 групп. Самые низкие приросты имели поросята чистопородного разведения. Таким образом, скрещивание крупной белой породы с СТ и помесных маток КБ х СТ с хряками специализированных мясных пород П, Д и Л, способствовало повышению репродуктивных качеств, где наряду с увеличением многоплодия выросла живая масса гнезда при отъеме и сохранность молодняка в сравнении с чистопородным разведением свиней КБ.

При этом наиболее результативным по воспроизводительным качествам являлись сочетания помесных маток КБ х СТ с хряками ландрас и дюрок.

Подсвинки различных вариантов скрещивания по всем показателям откормочных качеств достоверно превосходили сверстников КБ.

Одним из основных показателей интенсивного развития свиней является скороспелость, которая тесно связана со среднесуточным приростом живой массы. При анализе выявлено, что более высокие показатели по возрасту достижения живой массы 100 кг имели трехпородные подсвинки от сочетания (КБ х СТ) х Д, которые превосходили по скороспелости аналогов первой и второй группы соответственно на 12 ( $>>0,999)$ и 7 дн. (P>0,999). Они также имели 
преимущество по сравнению с животными 3 и 4 группы, соответственно на 2 и 3 дн.

Подсвинки от трехпородного сочетания (КБ хСТ) х П и (КБ х СТ) х Л также имели преимущество по скороспелости по сравнению с животными контрольной группы и помесями (КБ х СТ), соответственно, на 10 (Р>0,999) и 5 (Р>0,999) дн. и 9 (Р>0,999) и 4 дн. (Р>0,999).

Как более скороспелые подсвинки, (КБ х СТ) хД характеризовались и высокой энергией роста и превосходили животных контрольной группы на 89 г (Р>0,999), 2-ю группу КБ х СТ на 44 г (Р>0,999).

По среднесуточным приростам подсвинки 3, 4 группы также превосходили животных 1 и 2 группы соответственно на 84 (Р>0,999) и 39 г (Р>0,999); 75 (Р>0,999) и 30 г (Р>0,999).

Помесные подсвинки КБ х СТ имели преимущество на 45 г по сравнению со сверстниками КБ.

Подсвинки всех вариантов трехпородного скрещивания затрачивали на 1 кг прироста живой массы 3,5 -3,6 корм. ед. или на 0,3-0,4 корм. ед. меньше в сравнении с животными КБ.

Таким образом, результаты откормочных качеств подопытных подсвинков свидетельствуют о том, что использование хряков специализированных мясных пород в разных вариантах трехпородного скрещивания улучшает скороспелость, энергию роста и конверсию корма. При этом более результативным оказалось сочетание (КБ х СТ) х Д, которое имело достоверное превосходство над чисто породными сверстниками КБ и над помесными животными КБ х СТ.

Анализ результатов контрольного убоя свидетельствует, что по предубойной массе различия между подопытными животными были не значительными. 
По массе головы подсвинки трехпородного скрещивания уступали чистопородным сверстникам КБ на 0,1- 0,2 кг, а двухпородным подсвинкам КБ х СТ на 0,2-0,3 кг (Р<0,95).

Наибольшее количество почечного жира у двухпородных подсвинков КБ х СТ, затем следует КБ и подсвинки всех вариантов трехпородного скрещивания. Однако разница статистически не достоверна.

Масса туш у животных подопытных групп колебалась от 60,7 до 65,3 кг, а наибольшей массой туши характеризовались подсвинки 3-й, 4-й и 5-й групп, которая составила 64,2 - 65,3 кг, при этом наивысший показатель у сочетания (КБ х СТ) х Д - 65,3 кг.

Самый высокий убойный выход имели трехпородные подсвинки 72,4-73,3\% против 69,4\% у КБ, у двухпородных помесей КБ х СТ убойный выход составил - 70,5\%.

Одной из главных задач наших исследований являлось изучение мясных качеств потомства полученного при скрещивании свиноматок КБ и полукровных КБ х СТ с хряками специализированных мясных пород (пьетрен. дюрок, ландрас).

Анализ оценки мясных качеств полученного потомства при убое молодняка живой массы 100 кг приведены. Одним из важных показателей, характеризующих мясность туш, являются их линейные размеры, которые являются косвенным показателем мясной продуктивности. Самые длинные полутуши имели подсвинки всех вариантов трехпородного скрещивания 97,9; 98,1; 98,4 см которые превосходили сверстников КБ на 2,6 (Р>0,95); 2,8 (Р>0,99) и 3,1 см (Р>0,999), а двухпородных помесей КБ х СТ соответственно на 2,8 (P>0,99); 3,0 ( $\mathrm{P}>0,999)$ и 3,3 см ( $\mathrm{P}>0,999)$.

Наиболее тонкий слой шпика имели трехпородные подсвинки (КБ х СТ) х Д - 27,1 мм, и разница по этому показателю в сравнении с животными контрольной группы составило - 13,7\% (Р>0,999). 
У подсвинков (КБ хСТ) х П и (КБ х Т) х Л толщина шпика составила соответственно 27,4 и 27,3 мм и была меньше, чем у сверстников контрольной группы на 12,8 (Р>0,999) и 13,1\% (Р>0,999). Животные от сочетания КБ х СТ имели самую большую толщину шпика 31,8 против 31,4 мм у сверстников КБ.

Площадь «мышечного глазка» является важным показателем оценки мясности туши. Самое высокий показатель площади «мышечного глазка» был у подсвинков, полученных при скрещивании помесных маток КБ х СТ с хряками П, Л и Д - 32,2; 32,7; и 33,6 см², и был выше свиней КБ на $3,7 \mathrm{~cm}^{2}(\mathrm{P}>0,999) ; 4,2 \mathrm{~cm}^{2}(\mathrm{P}>0,999) ; 5,1 \mathrm{~cm}^{2}$ (Р>0,999). Животные 2 группы (КБ х СТ) по площади «мышечного глазка» на 0,4 см$^{2}$ отставали от налогов КБ.

По массе задней трети полутуши установлено достоверное преимущество опытных подсвинков 3, 4, 5 групп над чистопородными сверстниками КБ соответственно на 0,7 (Р>0,999); 0,9 (P>0,999) и 1,1 кг (P>0,999). Помесные подсвинки 2 группы по этому показателю превосходили животных контрольной группы на 0,2 кг $(\mathrm{P}<0,95)$.

Среди опытных групп трехпородные подсвинки (КБ х СТ) х Д имели преимущество по массе окорока над 3 и 4 группой на 0,2- 0,4 кг (P< $0,95)$.

Таким образом результаты исследований по мясным качествам доказывают, что самые высокие показатели имели трехпородные помеси (КБ х СТ) х Д, у которых длина туши, толщина шпика, площадь «мышечного глазка» и масса задней трети полутуши составили соответственно - 98,4 см, 27,1 мм,33,6 см², и 11,0 кг.

Данные морфологического состава туш свидетельствуют, что подсвинки, полученные от скрещивания помесных маток (КБ х СТ) с хряками пьетрен, ландрас, дюрок по выходу мяса в туше превосходили КБ и помесных маток КБ х СТ соответственно на 2,6 \% (Р>0,999); 3,3\% 
$(\mathrm{P}>0,999) ; 4,0 \% \quad(\mathrm{P}>0,999) \quad$ и $\quad 3,9 \quad \% \quad(\mathrm{P}>0,999) ; \quad 4,5 \quad \% \quad(\mathrm{P}>0,999) ; \quad 5,3 \%$ $(\mathrm{P}>0,999)$.

По количеству сала в туше выделялись животные 1-й и 2-й групп 30,8 и $32,1 \%$, которые превосходили животных трехпородного скрещивания на $2,5(\mathrm{P}<0,95) ; 3,0(\mathrm{P}<0,95) ; 3,8 \%(\mathrm{P}>0,99)$ и 3,9 $(\mathrm{P}>0,999)$; 4,3 ( $\mathrm{P}>0,999) ; 5,1 \%(\mathrm{P}>0,999)$.

По содержанию костей, различия не значительны и статистически недостоверны.

Всё это свидетельствует о том, что для увеличения производства мясной свинины и снижения ее себестоимости перспективным является создание племенных репродукторов по разведению свиней пород дюрок, ландрас и пьетрен и товарных ферм по получению помесных свиноматок КБ х СТ и дальнейшего их использования в системе разведения свиней при скрещивании с хряками мясных специализированных пород.

\section{Литература}

1. Василенко В.Н. Эффективность промышленного скрещивания свиней / Филонов А.Н., Максимов Г.В., Максимов А.Г., Ленкова Н.В. // Главный зоотехник. - 2015. - № 7. - С. 11-18.

2. Емельянов А.М. Способы оценки отбора и подбора свиней ДМ-1 и СТ по показателям естественной резистентности. п.Персиановский, 2007 - 150 с.

3. Зацаринин А.А. Эффективность промышленного скрещивания в товарном свиноводстве / Ларина Е.К. // В сборнике: Актуальные проблемы ветеринарной медицины, пищевых и биотехнологий Материалы Всероссийской научно-практической конференции. - 2015. - С. 150-154.

4. Клименко А.И. Перспективы развития свиноводства / Третьякова О.Л. // В сборнике: Актуальные проблемы производства свинины материалы XXIV заседания межвузовского координационного совета по свиноводству. - 2015. - С. 6-10.

5. Козликин А.В. Анализ физико-химических свойств мяса и шпика чистопородных и помесных свиней / А.В. Козликин // Политематический сетевой электронный научный журнал Кубанского аграрного университета. - 2011. - №73. - С. 524-533.

6. Козликин А.В. Особенности гистологического строения некоторых органов чистопородных и помесных свиней / Донерян А.М., Степанова О.В. // В сборнике: Инновации в науке, образовании и бизнесе - основа эффективного развития АПКМатериалы Международной научно-практической конференции: В 4-х томах. 2011. - C. 255-257. 
7. Никульников В.С. Результаты гибридизации и межпородного скрещивания в свиноводстве / Кононенко Е.А., Атрохов А.И., Фатеева Ю.Н. // Ученые записки Орловского государственного университета. Серия: Естественные, технические и медицинские науки. - 2012. - № 6-1. - С. 389-391.

8. Тариченко А.И. Интерьерные особенности свиней специализированных пород / Козликин А.В., Лодянов В.В. // Вестник Донского государственного аграрного университета. - 2015. - № 1-1 (15). - С. 104-110.

9. Филатов А.А. Дефекты свинины в мясе свиней разных генотипов / Козликин А.В. // В сборнике: Современные технологии производства продуктов питания: состояние, проблемы и перспективы развития Материалы Международной научнопрактической конференции факультета биотехнологии, товароведения и экспертизы товаров. - 2014. - С. 95-96.

\section{References}

1. Vasilenko V.N. Jeffektivnost' promyshlennogo skreshhivanija svinej / Filonov A.N., Maksimov G.V., Maksimov A.G., Lenkova N.V. // Glavnyj zootehnik. - 2015. - № 7. - S. 1118.

2. Emel'janov A.M. Sposoby ocenki otbora i podbora svinej DM-1 i ST po pokazateljam estestvennoj rezistentnosti. p.Persianovskij, 2007 - $150 \mathrm{~s}$.

3. Zacarinin A.A. Jeffektivnost' promyshlennogo skreshhivanija $v$ tovarnom svinovodstve / Larina E.K. // V sbornike: Aktual'nye problemy veterinarnoj mediciny, pishhevyh i biotehnologij Materialy Vserossijskoj nauchno-prakticheskoj konferencii. - 2015. - S. 150-154.

4. Klimenko A.I. Perspektivy razvitija svinovodstva / Tret'jakova O.L. // V sbornike: Aktual'nye problemy proizvodstva svininy materialy XXIV zasedanija mezhvuzovskogo koordinacionnogo soveta po svinovodstvu. - 2015. - S. 6-10.

5. Kozlikin A.V. Analiz fiziko-himicheskih svojstv mjasa i shpika chistoporodnyh i pomesnyh svinej / A.V. Kozlikin // Politematicheskij setevoj jelektronnyj nauchnyj zhurnal Kubanskogo agrarnogo universiteta. - 2011. - №73. - S. 524-533.

6. Kozlikin A.V. Osobennosti gistologicheskogo stroenija nekotoryh organov chistoporodnyh i pomesnyh svinej / Donerjan A.M., Stepanova O.V. // V sbornike: Innovacii $\mathrm{v}$ nauke, obrazovanii i biznese - osnova jeffektivnogo razvitija APKMaterialy Mezhdunarodnoj nauchno-prakticheskoj konferencii: V 4-h tomah. - 2011. - S. 255-257.

7. Nikul'nikov V.S. Rezul'taty gibridizacii i mezhporodnogo skreshhivanija $v$ svinovodstve / Kononenko E.A., Atrohov A.I., Fateeva Ju.N. // Uchenye zapiski Orlovskogo gosudarstvennogo universiteta. Serija: Estestvennye, tehnicheskie i medicinskie nauki. - 2012. - № 6-1. - S. 389-391.

8. Tarichenko A.I. Inter'ernye osobennosti svinej specializirovannyh porod / Kozlikin A.V., Lodjanov V.V. // Vestnik Donskogo gosudarstvennogo agrarnogo universiteta. - 2015. № 1-1 (15). - S. 104-110.

9. Filatov A.A. Defekty svininy v mjase svinej raznyh genotipov / Kozlikin A.V. // V sbornike: Sovremennye tehnologii proizvodstva produktov pitanija: sostojanie, problemy i perspektivy razvitija Materialy Mezhdunarodnoj nauchno-prakticheskoj konferencii fakul'teta biotehnologii, tovarovedenija i jekspertizy tovarov. - 2014. - S. 95-96. 